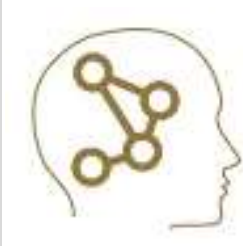

\title{
Is Turing Test Still Proficient and Operative at Present State of the ART?: Beyond Turing Test For The Next Generation Al Frameworks
}

\author{
Burhan Yarkin Calik \\ Hacettepe University Department of Philosopy, Ankara, Turkey. (e-mail: bcalik@ hacettepe.edu.tr)
}

\section{ARTICLE INFO}

Received: Aug.,11.2021

Revised: Oct, 18.2021

Accepted: Nov.,15.2021

Keywords:

Classification

Breast cancer

Deep learning

Image processing

Thermography

Corresponding author: Burhan Yarkin

Calik

$₫$ bcalik@hacettepe.edu.tr

iㅛ

ISSN: 2548-0650

\begin{abstract}
The problem of consciousness in terms of artificial intelligence is a difficult and big problem. With the test he put forward, the efficiency of artificial intelligence was discussed and tested. Some scientists have criticized the inability to distinguish between humans and robots with the Turing Test. Problems such as how sufficient this is and how it is possible to compare the intelligence of a human with the intelligence of a robot have been handled philosophically. The main purpose of this article is to address the adequacy of Turing testing and to question artificial intelligence tests and tools that can shed light on shaping the design of next-generation AI architectures. Searle's Chinese room experiment has been reconsidered by Turing by addressing the subjectivity-objectivity problem of Qualia philosophers and giving place to criticisms that can be directed to this test and countercriticisms that can be made to these criticisms. In addition, the role of the new generation Turing test in modeling concepts such as artificial consciousness and machine self-awareness and evaluating their performance is discussed.
\end{abstract}

DOI: https://doi.org/10.52876/jcs.1036777

\section{INTRODUCTION}

$\mathrm{A}_{\mathrm{n}}^{\mathrm{L}}$ LAN M. TURING, one of the most important mathematicians of the century by putting forward his ideas that will form the basis of computers, said, "Can machines replace humans? "How can we show it, whether it can or not?" He is known as the architect of the Turing test looking for answers to his questions. We can summarize Turing's thought experiment as follows. A computer stays out of sight with a human. The tester asks questions and tries to understand which is a human and which is a computer-based answer to the questions. If it cannot be determined which is which, the machine has passed the test. It was able to disguise itself, so this computer can be called artificial intelligence.

The machine in the Turing test processes input data internally and provides outputs to evaluate behaviors. This corresponds to the concept of mind in the tradition called Functionalism in the history of philosophy. [1] In summary, being in a mental state is being in a functional state [2]. As it is seen, Turing evaluates the intelligence of the machine in his test as a functional tool. With similar logic, the mind also processes input information that is received by sensory stimuli and generates output as a result of a behavior $[3,4]$. When these outputs are considered, the final feature of the being, which has a function between the input and the output as a result of behavior determined by observation will be the behavior, in which the presence and absence of a mind, consciousness, and intelligence, and if any, how humanoid it is. However, the mind and consciousness cannot be considered as consisting of behaviors. According to the concept of logical behaviorism, which Gilbert Ryle put forward in his book [5], the behaviors exhibited by the machine are only a reflection of the concepts of mind and consciousness. Functionalism does not see the behavior itself as the mind, hence the concept and/or problem of the mind as a pseudo-problem. It does not take an attitude that reduces the mind to behaviors [2]. This is the biggest feature that distinguishes it from behaviorism.

Concerning this approach of functionalism, Searle, in his consciousness and language, mentions Turing as follows: "Instead of accepting that consciousness is essentially a subjective and qualitative phenomenon, the most people mistakenly assume that the essence of consciousness is a 
control mechanism as a bunch of abilities or skills regarding behaviors." [6] Searle states that the Turing test fails and proposes a thought experiment, just like Turing, to explain what the error of the Turing test is. The famous Chinese room experiment. To sum up, someone who doesn't understand anything in Chinese is locked in a room with lots of Chinese symbols and a program to answer Chinese questions. Let the input of the system consist of Chinese symbols in the form of questions. The output should consist of Chinese symbols in the form of answers to questions. In this case, we can assume that the program will give the questions to a native Chinese speaker. However, neither the person nor the system (the machine) inside the room can understand Chinese [7].

According to Searle, what we call artificial intelligence performs operations just like the Chinese in the experiment. But he never understands these processes. Searle does not treat the mind as something supernatural (the soul). With a materialistic approach, he states that the mind (just like photosynthesis, digestion, etc.) is a biological phenomenon. The machine in the Turing test has no consciousness. The machine is not aware of what it is doing. Just having zeros and ones is not enough to provide conscious or unconscious mental content [6]. This is where Searle opposes the Turing test and thinks that the test is leading us to error. Therefore, he states that it is not possible for 0 and 1's to have the human abilities we call understanding and awareness.

However, we can criticize Searle in many ways. The first criticism will be a criticism of the experiment. Even if the person who is closed in the Chinese room does not understand Chinese, that room is full of Chinese resources. Here, it will be not just the person that takes the input and outputs it, but the entire room the person is in [8]. Therefore, it is not so important how much this person knows or understands Chinese. In addition, especially nowadays, programs and machines that simply take an input and output an output are quite simple. Now, these systems have been overcome and much more complex systems have taken their place. "A chat program that is sophisticated enough to give the impression of intelligence should not have lists of input/outputs, but rather complex real-world models with which it can match elements in dialogue." [9]. Another study on this subject belongs to Thomas Nagel. This problem, known as the "Qualia" problem, is to show that consciousness cannot be reduced to a physical state. Therefore, individual subjective experiences can never be realized objectively [10].

\section{BEYOND TURING TEST FOR THE NEXT - GENERATION AI FRAMEWORKS}

Despite some shortcomings, the Turing Test is still valid in many ways. Both the Turing-NLG, GPT-2, and GPT-3 (Generative Pre-trainer Transformer), which Microsoft introduced in February 2020, still carry the underlying idea of the Turing Test. A language that can use deep learning to produce content similar to texts written by people was modeled as GPT-3 in June 2020 [11]. But if there is to be a question of consciousness, it is required a different paradigm beyond the Imitation Game.

With the new Turing Tests, artificial intelligence must go beyond imitation. What we call consciousness is much more than imitating human intelligence, it is the self-perception of itself and its environment without any human behavior or thought $[3,4]$. It should detect new information, store old information, and of course reuse it when necessary.

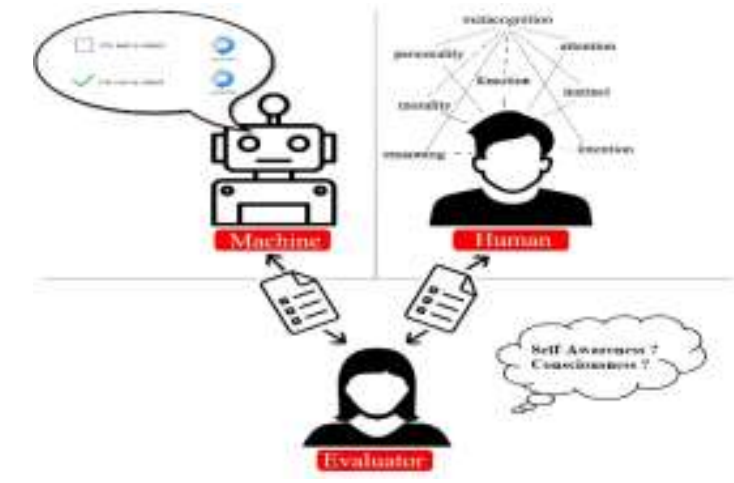

Fig. 1. Evaluation of the Turing test dealing with attributes of the human mind.

To summarize, they should act according to the goals they set themselves, without being programmed to set and make their own goals. Even if a smart vehicle that goes from point $\mathrm{X}$ to point $Y$ goes in the desired orbit, it cannot go beyond doing what it is told. The only way to overcome this stage is that the current Turing test should evolve beyond logical intelligence to evaluate human mental activities such as emotion, attention, intention, values/morality, instinct, awareness, metacognition, responsibility, regret, reasoning/inference so that the next-generation artificial intelligence models evaluated by these evolved testing tools are developed.

\section{CONCLUSIONS}

In terms of the theory of mind and human cognition, this article discusses how the Turing test may evolve to shape the next generation of AI models in the future. This article also includes studies that criticize the conventional form of the Turing test dealing with logical intelligence. Searle's Chinese room experiment and the Qualia problem are just two of the criticisms that can be leveled against the Turing approach. According to these ideas, the conventional form of the Turing test dealing with logical intelligence should be improved so that self-aware autonomous machines (humanoids, UAV/UGV, etc.) with next-generation AI (super artificial intelligence) which can be expressed as artificial general intelligence (AGI) or technological singularity can be realized.

\section{REFERENCES}

[1] Priest, S. (2018). Zihin Üzerine Teoriler (Dereko, A., Trans.). Istanbul: Litera, pp.205

[2] Bailey, A. (Ed.). (2013). Philosophy of mind: The key thinkers. A\&C Black, pp. 148.

[3] Daglarli, E. (2020). Computational Modeling of Prefrontal Cortex for Meta-Cognition of a Humanoid Robot. IEEE Access, 8, 98491-98507.

[4] Daglarli E., (2020). A Cognitive Integrated Multi-Modal Perception Mechanism and Dynamic World Modeling For Social Robot Assistants, The Journal of Cognitive Systems, 5(2), 46-50.

[5] Ryle, G. (2011) Zihin Kavramı (Çelik, S. Trans.) Istanbul:Doruk

[6] Searle, J. (2005). Bilinç ve Dil. (Macit, M. \& Ozpilavcı, C., Trans.) Istanbul: Litera, pp. 29-30

[7] Searle, J. (2014). Zihnin Yeniden Keşfi. (Macit, M., Trans.) Istanbul: Litera, pp. 70.

[8] Heil, J. (2020). Zihin Felsefesi Çağdaş Bir Giriş (Bilgili M., Akbıyık S. Trans). Kure, pp. 187.

[9] Say, C. (2021). 50 Soruda Yapay Zeka. Istanbul: Bilim ve Gelecek Kitaplığı, pp. 164.

[10] Nagel, T. (2012). Mind and Cosmos: Why the Materialist NeoDarwinian Conception of Nature Is Almost Certainly False. New York: Oxford University Press.

[11] Floridi, L., \& Chiriatti, M. (2020). GPT-3: Its nature, scope, limits, and consequences. Minds and Machines, 30(4), 681-694. 


\section{BIOGRAPHY}

Burhan Yarkm Calık is a senior student at Hacettepe University Philosophy Undergraduate Program, Hacettepe University Biology Undergraduate Program, and Istanbul University Veterinary Technician Associate Program. He works on the Philosophy of Mind, Consciousness, Body, and Language. He deals with the Philosophy of Cognitive Science and the place of Philosophy in Cognitive Science. He continues to work on the role of consciousness in Man, the body, and other living things. 